
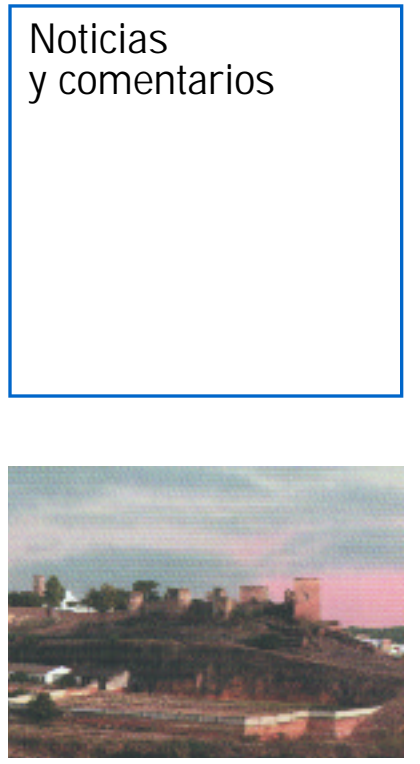

Detalle del folleto del congreso

\section{La integración de las fortificaciones en el espacio urbano centra el debate del congreso sobre "Paisaje y Fortificación"}

Entre los dias 1 y 5 de marzo se celebró en Alcalá de Guadaira (Sevilla) la tercera edición del Congreso Internacional sobre Fortificaciones, dedicada en esta ocasión al tema "Paisaje y Fortificación".

Al igual que en las ediciones anteriores, los argumentos tratados se han estructurado mediante una serie de ponencias y un nutrido conjunto de comunicaciones a través de diversos bloques temáticos:

$>$ Las fortificaciones como paisajes culturales.

> Los "paisajes fortificados", desde una perspectiva histórico-arqueológica y multidisciplinar.

> Análisis ambiental de entornos fortificados.

La conferencia de clausura corrió a cargo de la arquitecta Cristiana Storelli, experta del Consejo de Europa sobre políticas urbanas y miembro del equipo redactor de la Carta Europea del Paisaje. En su intervención, bajo el título genérico de Paysage et fortification: entre passé et futur, delineó los principales aspectos asociados a la interpretación de los recintos fortificados en relación con los espacios urbanos, y sus posibilidades como elementos identitarios a la vez que articuladores de una política cultural orientada hacia los ciudadanos.

Junto con las jornadas científicas, el Congreso ha desarrollado un conjunto de actividades complementarias, dentro de la idea de convertir la celebración de este evento no sólo en un foro de especialistas e interesados en la materia, sino también en escenario de participación. En este sentido, meses antes del Congreso se convocó el concurso "Los castillos en los cuentos", con participación de los colegios de la localidad y amplio número de contribuciones por parte del alumnado. La entrega de premios, realizada en la sesión inaugural del Congreso, se completó con la inauguración de la exposición itinerante "Los castillos ante el reto de su conservación", patrocinada por la Dirección General de Bienes Culturales.

Entre las ideas que pueden extraerse de las aportaciones científicas al Congreso, cabe destacar las siguientes:

> Todavía hoy existe una imagen excesivamente pintoresca de la arquitectura defensiva. En buena medida, ello responde a la herencia del romanticismo y su "idea de la ruina", pero también en muchos casos al excesivo planteamiento monumentalista de las Administraciones encargadas de la gestión de este Patrimonio Fortificado.
$>$ El conocimiento científico sobre estos recintos fortificados (desde una perspectiva transhistórica) presenta todavía una fuerte carga arqueológica o arquitectónica, por lo que muchas veces los "paisajes fortificados" siguen interpretándose de forma academicista. No obstante, se puede apreciar en los últimos años un incremento de las visiones multi e interdisciplinares sobre las fortificaciones, que ponen el acento en nuevos aspectos de interés, tales como las relaciones geográficas y paisajísticas con el entorno o específicamente los problemas de inserción ambiental y urbanística.

> En los niveles de protección, conservación y puesta en valor actuales, parece que las politicas respecto a los espacios fortificados tienden cada vez más, en línea con los planteamientos normativos más avanzados, hacia una aproximación integrada en el planeamiento urbanistico y la protección ambiental (medioambiental y cultural), centrada en la elaboración de análisis integrados y herramientas de protección y planificación asimilables en el planeamiento general.

Todos estos aspectos inciden en una evidencia: la necesaria superación del monumentalismo, entendido como actuación específica sobre el elemento aislado de su entorno y contexto. De ahi la necesidad de profundizar en el conocimiento (en muchos casos incluso el reconocimiento) arqueológico y arquitectónico, pero a la vez integrar esta perspectiva en una más amplia que contemple los desarrollos urbanísticos y territoriales en los que se inserta, con los que se relaciona y que afectan al bien. Ejemplos como el de la propia ciudad de Sevilla, cuya visita centró la última jornada del Congreso, evidencian hasta qué punto todavía carecemos en muchos casos de esa visión integradora, pues con frecuencia se protegen de forma dispersa elementos homogéneos que, como puede ser el recinto amurallado de la capital andaluza, todavía presentan profundas carencias de conocimiento e investigación, así como una ausencia casi total de políticas de interpretación y puesta en valor.

Al término de la última sesión del congreso quedó anunciada la siguiente edición, que tendrá lugar en esta misma ciudad en febrero o marzo de 2007 con el lema "Las fortificaciones y el mar".

Enrique Luis Domínguez Berenjeno Secretario Técnico III CIF 